\title{
Conhecimento e uso do ouricuri (Syagrus coronata) e do babaçu (Orbignya phalerata) em Buíque, PE, Brasil
}

\author{
Márcio Ulisses de Lima Rufino ${ }^{1,3}$, Judas Tadeu de Medeiros Costa², Valdeline Atanasio da Silva² e \\ Laise de Holanda Cavalcanti Andrade ${ }^{2}$
}

Recebido em 18/01/2008. Aceito em 15/07/2008

\begin{abstract}
RESUMO - (Conhecimento e uso do ouricuri (Syagrus coronata) e do babaçu (Orbignya phalerata) em Buíque, PE, Brasil). O Nordeste do Brasil abriga 80 espécies de palmeiras nativas, com baixo endemismo (27,5\%), algumas delas ameaçadas pelas alterações destrutivas do habitat natural, associadas à exploração desordenada. Investigou-se do ponto de vista etnobotânico a importância do ouricuri (Syagrus coronata) e do babaçu (Orbignya phalerata) em uma comunidade estabelecida junto ao Parque Nacional Vale do Catimbau, município de Buíque, Pernambuco. A importância atribuída pelo povo local para essas espécies foi analisada sob os seguintes aspectos: número de usos, número de informantes que faziam uso de seus produtos diretos ou indiretos; grau de consenso entre os informantes referentes aos usos relatados. Os dados foram obtidos através de entrevistas semi-estruturadas (60 informantes) e de índices baseados em técnicas de consenso do informante. Foram citadas sete categorias de uso: alimento do homem; alimento de animais domésticos; alimento de animais silvestres; construção; artesanato; combustível; medicinal. Apesar da diversidade de usos $(S c=33 ; O p h=25)$, a importância das duas espécies está relacionada predominantemente ao aproveitamento da amêndoa, como mostram os índices de valor para frutos $(S c=0,48$; $O p h=0,56)$. Analisando a contribuição de cada espécie para o uso total, o ouricuri apresentou maior valor $(8,58)$ em relação ao babaçu $(6,31)$. Sinais de um processo de erosão do conhecimento foram observados, com vários usos apontados como não mais praticados na comunidade, particularmente os associados ao artesanato.
\end{abstract}

Palavras-chave: Arecaceae, comunidades rurais, etnobotânica, palmeiras, vale do Catimbau

\begin{abstract}
Knowledge and use of ouricuri (Syagrus coronata) and babaçu (Orbignya phalerata) in Buíque, Pernambuco State, Brazil). The palm tree flora of Brazilian Northeast includes 80 native species, with a low level of endemism (27.5\%), some of them threatened by the destructive alterations of the natural habitat, associated to disordered exploration. This study investigated the importance of the ouricuri (Syagrus coronata) and the babaçu (Orbignya phalerata) in a community established near the Catimbau Valley National Park, Buíque municipality, Pernambuco state. These species' importance to the local population was analyzed based on the following aspects: number of uses, informant number who utilize their products directly or indirectly; informants' concensus level of the reported uses. The data was obtained from semi-structured interviews (60 informants) and from indexes based on informant consensus techniques. Seven use categories were cited: human food, domestic animal food, wild animal food, construction, folk art, fuel, medicine. Despite of the diversity of uses $(S c=33 ; O p h=25)$, the two species' importance is predominantly linked to the almond's usage - as shown by the fruit value indexes $(S c=0.48 ; O p h=0.56)$. Analyzing each species' contribution to the total use, the ouricuri had a higher value (8.58) in relation to the babaçu (6.31). Indications of a knowledge erosion process were observed, and the informants pointed out that several uses were no longer practiced in the community - especially those linked to folk art.
\end{abstract}

Key words: Arecaceae, rural community, ethnobotany, palm tree, Catimbau valley

\section{Introdução}

Representantes da família Arecaceae ocupam um lugar importante na composição da flora e da paisagem, tanto da faixa costeira como do interior dos diferentes estados que compõem a Região Nordeste do Brasil. Pernambuco não foge à regra, com o registro de 18 espécies de palmeiras, algumas delas praticamente restritas ao Nordeste do Brasil, como Syagrus coronata
(Mart.) Becc., conhecido como ouricuri ou licuri (Bondar 1938; Medeiros-Costa 2002). Como se verifica em todas as regiões onde representantes desta família estão presentes como espécies nativas, diversos produtos são obtidos dos diferentes órgãos das palmeiras. Dentre as 16 espécies destacadas por Medeiros-Costa (2002) pela sua reconhecida importância econômica em Pernambuco, o ouricuri e o babaçu (Orbignya phalerata Mart.) se incluem como importantes recursos vegetais.

\footnotetext{
1 Programa de Pós-Graduação em Biologia Vegetal, Mestrado, Centro de Ciências Biológicas, Universidade Federal de Pernambuco, Av. Prof. Moraes Rego s.n., Cidade Universitária, 50670-901 Recife, PE, Brasil

2 Universidade Federal de Pernambuco, Centro de Ciências Biológicas, Departamento de Botânica, Laboratório de Etnobotânica e Botânica Aplicada, Av. Prof. Moraes Rego s.n., Cidade Universitária, 50670-901 Recife, PE, Brasil

3 Autor para correspondência: marcioulisses@gmail.com
} 
Embora a maioria das palmeiras ocorrentes no Brasil não esteja incluída entre as espécies ameaçadas de extinção, o uso desordenado torna algumas delas vulneráveis, como é o caso do ouricuri, apontado por Silva et al. (2006) como praticamente desaparecido em Águas Belas, no sertão pernambucano e municípios vizinhos, pelo intensivo uso para fins artesanais tradicionalmente praticados pelos Fulni-ô.

O conhecimento sobre as espécies de palmeiras que ocorrem em Pernambuco é quase que ausente, sendo praticamente restrito às informações de cunho taxonômico e distribuição geográfica fornecidas por Medeiros-Costa (2002). As espécies nativas, pertencentes a sete gêneros, habitam as três regiões fisiográficas do estado (Litoral-Mata, Agreste e Sertão); ocorrem em ecossistemas de grande diversidade florística, pouco conhecidos cientificamente e fortemente ameaçados, tais como a Mata Attântica, a Caatinga e os Brejos de Altitude (Medeiros-Costa 2002). São poucas as informações do tipo das fornecidas por Albuquerque $\&$ Andrade (2002), que relatam o uso para sombreamento de uma espécie não identificada de Bactris, e o uso do coqueiro (Cocos nucifera L.) como alimentícia, no município de Alagoinha, agreste pernambucano.

Crepaldi et al. (2001) realizaram um estudo sobre a composição nutricional do fruto do ouricuri e destacaram o teor de lipídios $(49,2 \%)$ e proteínas $(11,5 \%)$ da amêndoa e o teor de carboidratos totais da polpa dos frutos $(13,2 \%)$. O teor de lipídios é elevado e similar ao padrão encontrado para outras espécies de palmeiras porém o teor de proteínas é maior do que o encontrado em frutos de espécies de palmeiras amazônicas. O teor de carboidratos totais da polpa do ouricuri é semelhante ao de espécies amazônicas, com exceção de Euterpe oleracea Mart., o açaí ou juçara $(57,4 \%)$ e Bactris gasipaes H. B. K., a pupunha (14,5 a 84\%). O $\beta$-caroteno é a principal vitamina encontrada na polpa dos frutos do ouricuri, e mesmo sendo encontrado em um teor menor $\left(2,6 \mu \mathrm{g} \cdot \mathrm{g}^{-1}\right)$ que o de outras espécies de palmeiras, ainda é uma boa fonte dessa vitamina, sobretudo porque em períodos de seca severa constitui-se no único alimento disponível na vegetação (Crepaldi et al. 2001). Segundo Medeiros Costa (2002), além do babaçu e do ouricuri há importância econômica reconhecida em Pernambuco para muitas espécies que ocorrem no nordeste do país, como Acrocomia intumescens Drude (macaíba), Atallea oleifera Barbosa Rodrigues (pindoba), Bactris ferruginea Burret (coco-de-fuso), Copernicia prunifera (Miller) H.E. Moore (carnaúba), Syagrus cearensis Noblick (catolé) e Syagrus x costae Glassman (catolé) como frutíferas ou fornecedoras de óleo, cera e fibras. O uso medicinal, alimentício, tecnológico, comercial e/ou mágico de algumas dessas palmeiras, como a macaíba, o coqueiro, o coco-de-fuso e o coco catolé, bem como o maraial (Bactris sp.) e a titara (Desmoncus sp.), foi relatado por Gazzaneo et al. (2005) e Silva \& Andrade (2005), em estudos realizados junto a comunidades do Litoral Norte de Pernambuco.

Informações de cunho etnobotânico podem esclarecer o nível de dependência de uma comunidade em relação aos recursos vegetais locais e fornecer informações sobre as conseqüências de determinados tipos de exploração dos recursos (Philips 1996). No Brasil, o fracasso de muitos projetos que visavam reduzir a pressão antrópica no ambiente ou promover o desenvolvimento econômico de uma região deve-se, em parte, ao fato de não se levar em consideração o apoio e envolvimento das comunidades locais, valorizando o que elas percebem como importante ou como fonte de problemas durante o planejamento e implantação dos projetos de conservação e desenvolvimento, como apontaram Byg \& Baslev (2001) para Madagascar.

Conhecer quais as necessidades locais atendidas com produtos obtidos de palmeiras, seus padrões de utilização, quais os grupos sociais mais dependentes dos recursos oferecidos pelas palmeiras ou como os mesmos são extraídos, torna-se necessário tanto do ponto de vista científico como econômico e conservacionista. É também necessário investigar a percepção local sobre a importância das palmeiras pois, além de integrarem o sistema de valores de uma cultura, tais saberes são também importantes para o êxito de práticas voltadas para a conservação do ambiente biológico (Byg \& Baslev 2001). As mudanças que ocorrem nas comunidades levam a novos modos de vida e, frequentemente, ao abandono das práticas de exploração dos recursos vegetais. Neste caso, segundo Philips \& Gentry (1993), apenas os membros mais idosos ou aqueles de uma determinada classe sócio-econômica retém o conhecimento original.

São escassas as informações sobre quais as necessidades locais atendidas por produtos obtidos das espécies de palmeira ocorrentes em Pernambuco, como o conhecimento sobre seus usos está distribuído nas populações do agreste e sertão e quais as partes das plantas de maior interesse. Com base nessas considerações, desenvolveu-se um estudo de cunho etnobotânico nas proximidades do Parque Nacional Vale do Catimbau, uma das poucas Unidades de Conservação estabelecidas dentro do bioma Caatinga, no agreste de Pernambuco. Objetivou-se definir a contribuição de duas espécies, o ouricuri e o babaçu, no dia a dia dos membros de uma comunidade estabelecida na zona rural do município de Buíque; avaliou-se as partes das plantas de maior importância, registrou-se a diversidade de usos antigos e atuais de cada espécie e investigou-se como o conhecimento está distribuído na população. 


\section{Material e métodos}

Área de estudo - Como acontece com a maioria da população do Brasil que habita a Caatinga, a comunidade rural estudada é extremamente pobre e os longos períodos de seca determinam uma baixa produtividade da região, à qual se associam a agricultura de corte e a queima, o corte de madeira para lenha, a caça de animais e a contínua remoção da vegetação para a criação de bovinos e caprinos, que também têm levado à perda da diversidade biológica (Leal et al. 2005). O município de Buíque, onde se situa a área de estudo, dista $285 \mathrm{~km}$ do Recife e está localizado no agreste de Pernambuco

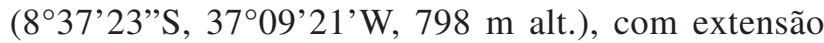
territorial de $127.969 \mathrm{~km}^{2}$. A população, constituída em 2004 por 47.271 habitantes, instalou-se na região em 1752, sendo o povoado elevado à categoria de vila em 1854. Além do distrito sede, o município compreende os distritos de Catimbau, Carneiro, Guanabi, o povoado denominado Tanque e a aldeia dos Kapinawá, um dos sete grupos indígenas remanescentes de Pernambuco.

Originalmente constituída por trabalhadores da Fazenda São José, da qual foram dispensados após a morte do dono, a comunidade estudada se estabeleceu nos anos 1970 no distrito de Carneiro, nas localidades Sítio Baixa Grande e Sítio do Serrote Preto, onde existem atualmente cerca de 40 residências distribuídas no entorno daquela propriedade, nas quais moram cerca de 300 pessoas, entre crianças, jovens, adulto e idosos; os dois Sítios encontram-se nas proximidades do Parque Nacional Vale do Catimbau, o segundo parque arqueológico do país e importante sítio indígena, com 90.000 ha transformados recentemente pelo governo federal em Unidade de Conservação de Proteção Integral. As serras e morros desse município pertencem à Formação Tacaratu, que repousa discordantemente sobre o cristalino e aflora em diversos pontos da bacia sedimentar do Jatobá. Aquela formação apresenta arenitos quartzíticos grosseiros e conglomerados, cinza-claro ou arenitos finos cinzentos, amarelos ou róseos (Jacomine et al. 1977 apud Gomes et al. 2006). O clima é do tipo BS'hW (clima quente e seco), típico do semi-árido nordestino, com temperatura e precipitação médias anuais de $26{ }^{\circ} \mathrm{C}$ e $600 \mathrm{~mm}$, respectivamente, com maior precipitação entre os meses de abril a junho (Gomes et al. 2006). A presença humana é datada de 6.000 anos e, segundo comunicação pessoal da Dra. Suely Luna, pesquisadora da Universidade Federal Rural de Pernambuco, vários achados arqueológicos mostram o uso de palmeiras entre os recursos vegetais locais, pelos diversos grupos étnicos que viveram na região em diferentes épocas.

Coleta e análise de dados - $\mathrm{O}$ estudo baseou-se em entrevistas realizadas entre junho/2005 e julho/2006 junto a 33 mulheres e 27 homens que representam cerca de $60 \%$ do universo amostral, constituído por adultos e idosos ( $\geq 18$ anos). Todos os entrevistados concordaram em participar da pesquisa após serem informados do seu objetivo. A faixa etária dos informantes variou entre 18 e 82 anos, predominando a faixa entre 20 e 60 anos; a maioria tem a agricultura de subsistência como atividade principal e $74 \%$ cursaram as primeiras séries do ensino fundamental, não havendo recebido os demais instrução formal.

Durante as entrevistas, empregou-se formulário semi-estruturado com 23 ítens, com uma parte introdutória referente a dados pessoais do informante e outra parte com questões relacionadas ao uso de palmeiras na região, particularmente das duas espécies selecionadas. Os usos citados foram enquadrados nas seguintes categorias: alimento, subdividida em alimento do homem, alimento de animais domésticos (porco, galinha, cabra, bode, boi, vaca) e alimento de animais silvestres (pássaros e pequenos roedores); construção; artesanato; combustível; medicinal.

A importância de cada espécie foi analisada sob os seguintes aspectos: número de usos, número de informantes que faziam uso de seus produtos diretos ou indiretos; grau de consenso entre os informantes referentes aos usos relatados. Foram empregados os índices apresentados nos Quadros 1 e 2, adotando-se a metodologia descrita por Byg \& Baslev (2001) e Albuquerque \& Lucena (2004).

\section{Resultados e discussão}

Através das entrevistas obtiveram-se 498 citações de usos para o ouricuri e 366 para o babaçu, distribuídas nas categorias: alimento para o homem, alimento para animais domésticos, alimento para animais silvestres, construção, artesanato, combustível e medicinal (Fig. 1).

O número de citações de uso para as duas espécies analisadas concorda com o observado por Phillips \& Gentry (1993) em estudo realizado no Peru; os referidos autores constataram que as palmeiras eram mais utilizadas que espécies de outras famílias de tamanho comparável, citadas pelos mesmos entrevistados. Este fato foi também observado por Pinheiro et al. (2005) para cinco comunidades assentadas na Baixada Maranhense; esta questão não pode ser respondida no presente estudo pois apenas duas espécies de palmeiras foram enfocadas e não se dispõe de trabalhos semelhantes efetuados com outras famílias botânicas para o local.

De um total de 14 espécies de palmeiras registradas em um levantamento efetuado em floresta secundária no Pará, Rocha \& Silva (2005) observaram uma baixa 
Quadro 1. Índices baseados em técnicas de consenso do informante relacionados às plantas (Byg \& Baslev 2001; Albuquerque \& Lucena 2004).

\begin{tabular}{|c|c|c|}
\hline Índices & Cálculo & Descrição \\
\hline Valor para parte da planta (PPV) & $\begin{array}{l}\text { Razão entre o número total de usos reportados } \\
\text { para cada parte da planta e o somatório de usos } \\
\text { reportados para aquela planta. }\end{array}$ & $\begin{array}{l}\text { Indica diferença no número de usos das partes da } \\
\text { planta e aponta a parte da planta mais utilizada. }\end{array}$ \\
\hline Diversidade total de espécies (SDtot) & $\begin{array}{l}\text { Número de vezes que uma espécie é citada, divi- } \\
\text { dido pelo número total de usos das espécies. }\end{array}$ & $\begin{array}{l}\text { Mede como muitas espécies são usadas e como } \\
\text { elas contribuem para o uso total. }\end{array}$ \\
\hline Equitabilidade total das espécies (SEtot) & $\begin{array}{l}\text { Diversidade total de espécies dividido pelo nú- } \\
\text { mero de espécies citadas. }\end{array}$ & $\begin{array}{l}\text { Mede como diferentes espécies contribuem para } \\
\text { o uso total independente do número de espécies } \\
\text { usadas. }\end{array}$ \\
\hline Valor da diversidade de uso (UDs) & $\begin{array}{l}\text { Número de indicações registradas por categorias } \\
\text { de uso dividido pelo número total de indicações } \\
\text { para todas as categorias. }\end{array}$ & $\begin{array}{l}\text { Mede como uma espécie é usada em uma catego- } \\
\text { ria e como contribui para o valor de uso total. }\end{array}$ \\
\hline Valor de equitabilidade de uso (UEs) & $\begin{array}{l}\text { Valor da diversidade de uso dividido pelo valor } \\
\text { máximo do referido índice. }\end{array}$ & $\begin{array}{l}\text { Mede como diferentes usos contribuem para o } \\
\text { uso total de uma espécie, independente do núme- } \\
\text { ro de categorias de uso. }\end{array}$ \\
\hline
\end{tabular}

Quadro 2. Índices baseados em técnicas de consenso do informante relacionados aos informantes (Byg \& Baslev 2001; Albuquerque \& Lucena 2004).

\begin{tabular}{|c|c|c|}
\hline Índices & Cálculo & Descrição \\
\hline $\begin{array}{l}\text { Valor da diversidade do informante } \\
\text { (IDs) }\end{array}$ & $\begin{array}{l}\text { Número de usos citados por determinado infor- } \\
\text { mante dividido pelo número de usos totais (to- } \\
\text { tal de citações de todos os informantes). }\end{array}$ & $\begin{array}{l}\text { Mede como muitos informantes usam uma espé- } \\
\text { cie e como o seu uso está distribuído entre eles. }\end{array}$ \\
\hline $\begin{array}{l}\text { Valor da equitabilidade do informante } \\
\text { (IEs) }\end{array}$ & $\begin{array}{l}\text { Valor da diversidade do informante dividido pe- } \\
\text { lo valor máximo do referido índice. }\end{array}$ & $\begin{array}{l}\text { Mede como o uso de uma planta está distribuído } \\
\text { entre os informantes independente do número } \\
\text { de informantes que usam a planta. }\end{array}$ \\
\hline Valor do consenso de uso (UCs) & $\begin{array}{l}\text { Razão entre o dobro de pessoas que usam a espé- } \\
\text { cie e o número de espécies citadas menos um. }\end{array}$ & $\begin{array}{l}\text { Mede o grau de concordância entre os informan- } \\
\text { tes com relação a uma espécie ser útil ou não. }\end{array}$ \\
\hline $\begin{array}{l}\text { Valor de consenso para um propósito } \\
\text { (PCs) }\end{array}$ & $\begin{array}{l}\text { Número de vezes que o uso foi citado para a es- } \\
\text { pécie dividido pelo número total de citações de } \\
\text { uso da espécie. }\end{array}$ & $\begin{array}{l}\text { Mede o grau de acordo entre os informantes } \\
\text { quanto às propostas de usos. }\end{array}$ \\
\hline
\end{tabular}

diversidade quanto ao número de usos de espécies dessa família, diferentemente do observado para o ouricuri e o babaçu no presente estudo. Esta diferença na

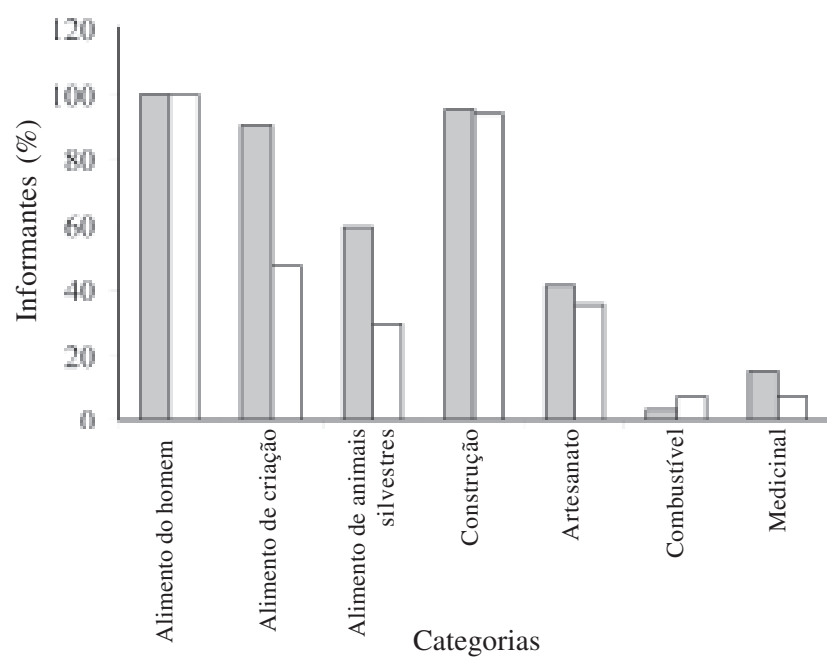

Figura 1. Categorias de uso citadas para Syagrus coronata (ouricuri) e Orbignya phalerata (babaçu) nos sítios Baixa Grande e Serrote Preto, Buíque, PE, Brasil ( $\square=$ Ouricuri; $\square=$ Babaçu). diversidade do número de usos pode ser explicada pela maior oferta de plantas de outras famílias com folhas perenes, presentes na área de floresta secundária estudada no Pará, em comparação com o observado. Entre as espécies vegetais utilizadas pelas comunidades do município de Penalva (Maranhão), o babaçu aparece como a de mais freqüente utilização (46,34\%); outras palmeiras são também bastante utilizadas, como o marajá (Bactris brongniartii Mart.) (5,69\%), o tucum (Astrocaryum vulgare Mart.) (4,87\%) e a juçara (4,06\%) (Pinheiro et al. 2005).

Os 32 usos para o ouricuri e 25 para o babaçu citados pelos informantes estão distribuídos em sete categorias, concentrando-se em alimento do homem e artesanato, com seis a nove usos, respectivamente. Essa multiplicidade de usos para babaçu e ouricuri corrobora o observado por Macía (2004), em estudo realizado com os índios Huaorani da Amazônia equatoriana, no qual as 37 espécies citadas são usadas, em sua maioria $(64,9 \%)$, na construção de casas e na alimentação humana, e mostram um número significativo de diferentes usos. 
Tabela 1. Índices de diversidade, equitabilidade e consenso de uso relativos a Syagrus coronata (ouricuri) e Orbignya phalerata (babaçu) no município de Buíque, PE, Brasil.

\begin{tabular}{lcc}
\hline Índice & Babaçu & Ouricuri \\
\hline Diversidade total de espécies (SDot) & 6,31 & 8,28 \\
Equitabilidade total de espécie (SEtot) & 3,15 & 4,29 \\
Diversidade do informante (IDs) & $0,12-0,52$ & $0,12-0,36$ \\
Equitabilidade do informante (IEs) & $0,23-1,0$ & $0,12-1,0$ \\
Consenso de uso (UCs) & 1,93 & 2,03 \\
\hline
\end{tabular}

Observa-se na Tab. 1 que os índices de diversidade de usos e equitabilidade do ouricuri atingiram valores um pouco mais elevados $\left(\operatorname{SDtot}_{s c} 8,58 ; \operatorname{SEtot}_{s c} 4,29\right)$ que o babaçu (SDtot ${ }_{O p h} 6,31 ;$ SEtot $_{O p h} 3,15$ ), talvez devido à menor facilidade de acesso às populações dessa palmeira, restritas a dois locais (ambientes de maior umidade), o Brejo de São José e o Sítio do Pico, distantes cerca de $5 \mathrm{~km}$ do local de moradia dos informantes, em contraposição à ampla distribuição do ouricuri.

Alimentação - Como alimento do homem todos os informantes reconheceram algum tipo de uso para o babaçu e o ouricuri (Fig. 2), também citados como alimento de animais domésticos e alimento de animais silvestres. O fruto foi a parte da planta mais citada como recurso alimentício para homem e animais, domésticos ou silvestres, destacando-se a amêndoa para as duas espécies de palmeira estudadas $\left(\mathrm{PPV}_{O p h} 0,56 ; \mathrm{PPV}_{S c} 0,48\right)$ e o mesocarpo $\left(\mathrm{PPV}_{S c} 0,06\right)$, comestível apenas para o ouricuri (Tab. 2). Em outras regiões do país onde ocorre o babaçu, como no Maranhão, frutos de palmeiras também têm grande utilização, principalmente como item alimentar, ao mesmo tempo em que geram renda como produto comercial, para a indústria de óleo, extraído das amêndoas (Pinheiro et al. 2005).

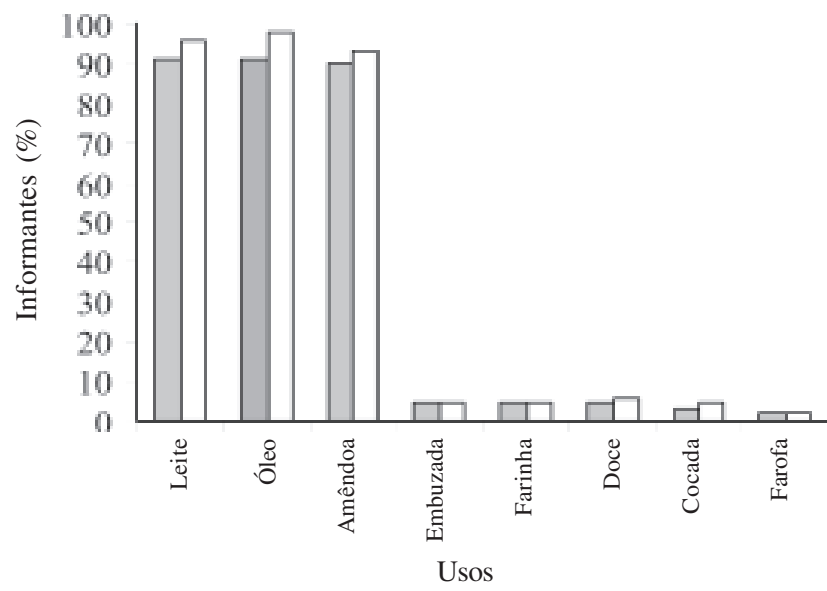

Figura 2. Citações de uso de Syagrus coronata (ouricuri) e Orbignya phalerata (babaçu) como alimento do homem nos sítios Baixa Grande e Serrote Preto, Buíque, PE, Brasil ( $\square=$ Ouricuri; $\square=$ Babaçu).
Como acontece em outras comunidades brasileiras que utilizam estas duas espécies de palmeira (Balick 1984), na comunidade estudada são extraídos óleo e "leite do coco" dos frutos do ouricuri e do babaçu, empregados no preparo de bebidas, como a embuzada (bebida preparada com o "leite do coco" e os frutos do umbuzeiro, Spondias tuberosa Arr.-Câm.) e comidas como cocada e outros doces. O óleo e o "leite do coco" das duas plantas são utilizados como tempero, com mais freqüência na época da semana santa, principalmente no preparo de pratos feitos com peixes. Para o babaçu, $31 \%$ dos informantes citaram o uso do óleo extraído do fruto no preparo de alimentos e $30 \%$ mencionaram o uso do "leite do coco" e da amêndoa in natura; apenas $2 \%$ dos informantes citaram o uso do fruto no preparo de embuzada, farinha, cocada e outros doces e muito poucos $(1 \%)$ citaram o uso do azeite dentre os produtos alimentícios obtidos dessa palmeira. São semelhantes os percentuais de citação referentes aos mesmos produtos alimentícios obtidos do ouricuri, assim distribuídos: $30 \%$ "leite do coco" e amêndoa in natura; $28 \%$ óleo do fruto; $3 \%$ cocada, mesocarpo, doce; $1 \%$ farofa da farinha e embuzada (Fig. 2). Desde a primeira metade do século passado Bondar (1938) chamava a atenção para a diversidade de produtos obtidos da amêndoa do ouricuri, consumida in natura e também utilizada para fabricação de cocadas, licores, sendo o "leite do coco" muito utilizado na culinária baiana e o óleo usado em culinária pela população do semi-árido nordestino.

Costa Neto (2004) menciona que a lagarta-doouricuri (Pachymerus nucleorum, Bruchidae) desenvolve-se no interior dos frutos já caídos e na Bahia é comida crua, junto com a "carne" do coco ou frita em seu próprio óleo, acompanhada de farinha de mandioca.

$\mathrm{Na}$ categoria alimento de animais domésticos enquadram-se espécies usadas como ração animal e na comunidade estudada $90 \%$ dos entrevistados citaram o fruto e o bagaço do ouricuri para este fim, enquanto apenas $47 \%$ dos entrevistados mencionaram o uso do bagaço de babaçu para esta mesma finalidade (Fig. 2). Pequenos produtores que habitam a Caatinga baiana preparam artesanalmente uma ração triturando frutos frescos e secos de ouricuri. A análise microbiológica

Tabela 2. Índice de valor de uso para as diferentes partes (PPV) de Syagrus coronata (ouricuri) e Orbignya phalerata (babaçu) no município de Buíque, PE, Brasil.

\begin{tabular}{lcc}
\hline Parte da planta & Babaçu & Ouricuri \\
\hline Amêndoa & 0,56 & 0,48 \\
Casca (pericarpo+mesocarpo) & 0,04 & 0,06 \\
Folha & 0,32 & 0,39 \\
Estipe & 0,08 & 0,06 \\
\hline
\end{tabular}


mostrou ser esta ração de boa qualidade, com baixa contagem de bactérias mesófilas, ausência de salmonelas e aceitável contaminação por fungos filamentosos e leveduriformes (Gonçalves et al. 2005).

Interessante notar que os ruminantes ingerem os frutos do ouricuri, consomem o mesocarpo e regurgitam a semente, que é conhecida na comunidade por "coco de arroto" e muito apreciada como alimento pela população local.

Além de entrarem rotineiramente na alimentação do homem na forma de frutos e palmito e até de produtos elaborados, como doces, bebidas e óleos, em outras regiões do país espécies dos gêneros Orbignya, Syagrus, Acrocomia e Mauritia servem de alimento para várias espécies da fauna silvestre, que consomem suas folhas, polpa dos frutos (canídeos) e sementes (roedores de pequeno e médio porte, psitacídeos etc.). No presente estudo, mais da metade dos informantes (59\%) reconheceram a semente do ouricuri como recurso alimentício para animais silvestres, mas apenas $29 \%$ citaram sementes de babaçu como alimento para pequenos roedores silvestres.

Construção - Folhas e caules de babaçu e ouricuri são as partes da planta utilizadas para construção de telhados, paredes, mourões, ranchos, barracas e banheiros. A quase totalidade de informantes (ouricuri, 95\%; babaçu, 94\%) reconheceu algum uso destinado à construção para essas palmeiras, particularmente telhados e paredes (Fig. 3). A folha é a principal parte da planta empregada nessas construções e o estipe é usado exclusivamente como mourão, o que explica o seu baixo valor de PPV (Tab. 2). Pinheiro et al. (2005) relatam que os principais produtos utilizados em Penalva, município da Baixada Maranhense, com maior frequiência, enquadram-se na categoria de material de construção e utensílios domésticos, sendo oriundos, principalmente, do babaçu; ao analisar a relação existente entre a categoria de uso e a parte da planta utilizada, os referidos autores constataram que, quando os usos se enquadram nas duas categorias citadas, as partes usadas serão, mais provavelmente, o caule e a folha, com maior freqüência provenientes de palmeiras, como o tucum, a juçara, o marajá e o babaçu (folha inteira).

Dentro da categoria construção, o ouricuri se destaca pela maior diversidade de usos, porém em outros locais onde o babaçu é mais abundante, como no Maranhão, o seu caule é um dos materiais preferidos para construção de casas e poços (Pinheiro et al. 2005). As folhas de $O$. oleifera, também conhecida como babaçu na Bahia, Minas Gerais e Mato Grosso, são referidas por Schwenk \& Silva (2000) como material empregado na construção de casas, como cobertura de telhados (folhas).

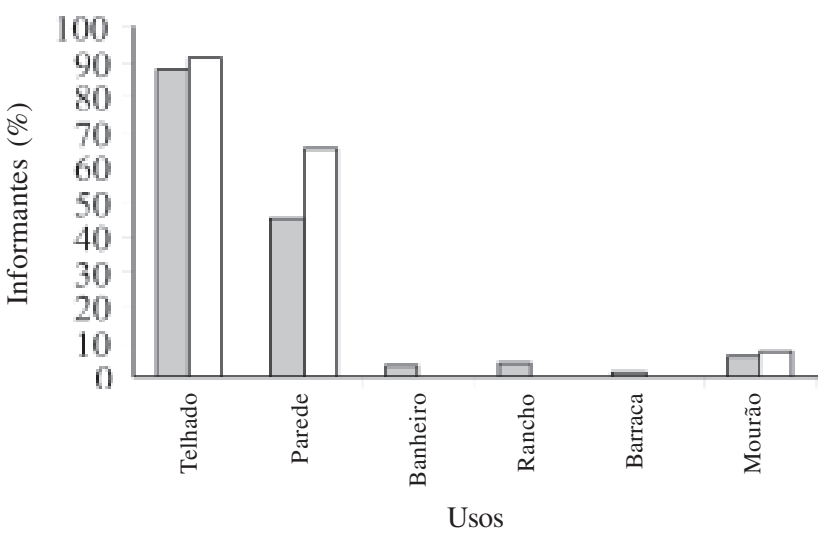

Figura 3. Citações de uso de Syagrus coronata (ouricuri) e Orbignya phalerata (babaçu) para construção nos sítios Baixa Grande e Serrote Preto, Buíque, PE, Brasil ( $\square=$ Ouricuri; $\square=$ Babaçu).

Artesanato - Para o ouricuri esta categoria foi citada por $41 \%$ dos informantes e a palha dessa palmeira é a parte usada para a fabricação dos seguintes artefatos: abano, bolsa, cesta, chapéu, corda, esteira, peneira, tapete e vassoura. A diversidade de artefatos e o uso corrente de alguns deles, como vassoura, levam a folha a constituir a segunda parte mais utilizada do ouricuri (Tab. 2). Das citações de uso artesanal, algumas correspondem a produtos que não são mais utilizados pela população devido à introdução de material industrializado similar, como chapéus e cestas, sendo de uso ainda corrente na comunidade as vassouras preparadas com as folhas secas do ouricuri (Fig. 4). Um total de 35\% dos entrevistados usa o babaçu para manufatura de abano, bolsa, cesta, chapéu, esteira e vassoura (Fig. 4) e, tal como no ouricuri, a folha é a segunda parte da planta mais utilizada pela comunidade (Tab. 2).

Embora exista coincidência em quase todos os produtos, maior número de citações se referiu à manufatura de esteira (42\%) e chapéu (22\%) com as folhas do babaçu, enquanto para o ouricuri se destacaram vassoura (24\%) e chapéu (23\%).

Durante as entrevistas, constatou-se que, na comunidade, os produtos artesanais obtidos do ouricuri e do babaçu são considerados como de qualidade inferior, sendo o uso de produtos industrializados, como chapéus e bolsas, um indicativo de melhor status social. Este comportamento se verifica em outras partes do Brasil e do mundo (Byg \& Baslev 2001), mas a facilidade atual de aquisição de produtos industrializados pela população do município provavelmente tem colaborado para a erosão do conhecimento tradicional relativo às duas espécies de palmeiras estudadas.

Combustível - Cerca de $7 \%$ dos informantes citou a lenha, proveniente do estipe, e o carvão, obtido a partir da casca do fruto do babaçu, como comburentes para uso em fogões domésticos. Também foi pequeno o 


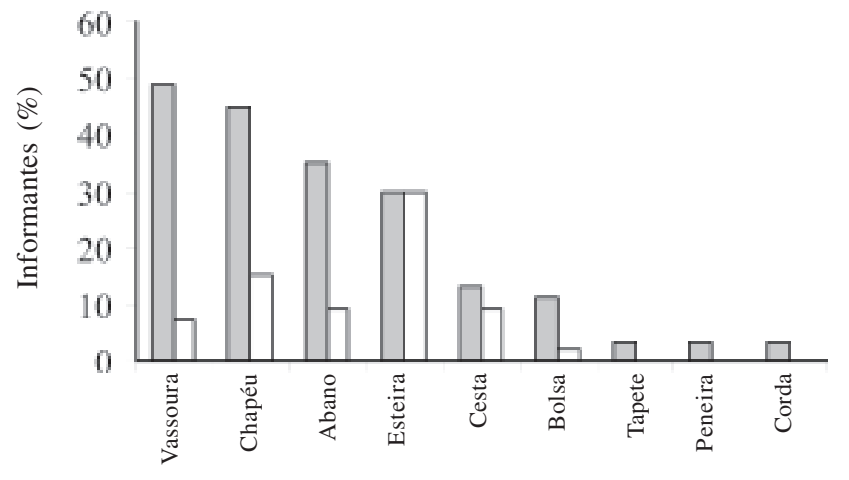

Usos

Figura 4. Citações de uso artesanal para Syagrus coronata (ouricuri) Orbignya phalerata (babaçu) nos sítios Baixa Grande e Serrote Preto, Buíque, PE, Brasil ( $\square=$ Ouricuri; $\square=$ Babaçu).

percentual (3\%) dos informantes que citaram o uso do ouricuri como lenha e todos esclareceram que utilizam apenas os indivíduos mortos naturalmente. $\mathrm{O}$ carvão obtido a partir do babaçu tem merecido atenção em vários estudos, chegando mesmo a ser considerado superior ao carvão obtido da madeira do eucalipto (Silva et al. 1986). Na comunidade estudada, todavia, o uso da casca do babaçu como carvão foi mencionado por poucos informantes, acarretando um baixo valor de PPV para essa parte da planta (Tab. 2).

Medicinal - Apenas $15 \%$ dos entrevistados conhecem uso medicinal para o ouricuri. Dentre as partes usadas estão a "água do coco" (endosperma), indicada como colírio para tratamento de inflamação ocular, micoses (pano preto e pano branco) e cicatrização de feridas; o chá da raiz do ouricuri é indicado para o tratamento de dores na coluna vertebral. O uso medicinal de uma lagarta não identificada que se desenvolve no fruto do ouricuri foi relatado por um dos informantes, sendo empregado na comunidade estudada para tirar manchas da pele decorrentes de feridas cicatrizadas.

Um baixo percentual de informantes $(7 \%)$ reconhece o babaçu como medicinal, usando o óleo extraído da amêndoa na cicatrização de feridas, no tratamento de micoses (pano branco e pano preto) e como laxante. A capacidade de cicatrização de feridas através de substâncias presentes no fruto de babaçu foi objeto de pesquisa de Amorim et al. (2006), cujos resultados demonstraram que o uso tópico do extrato aquoso do mesocarpo propiciou a cicatrização de feridas em ratos. Balick (1984), realizando estudos etnobotânicos em outras regiões do Brasil, refere o uso do óleo de babaçu misturado a açúcar como vermífugo e comenta que este mesmo óleo é empregado na Bolívia como remédio para gripe.

Os valores de consenso de uso encontrados entre os informantes foram elevados $\left(\mathrm{UCs}_{S c} 2,03 ; \mathrm{UCs}_{O p h} 1,93\right)$ mostrando que todos, ou quase todos, conhecem a utilidade das duas espécies, evidenciando o valor cultural destas palmeiras para a comunidade estudada (Tab. 1). Considerando o valor de consenso para um propósito (Tab. 3), que mede o grau de acordo entre os informantes para um determinado uso, os índices mais elevados para o ouricuri foram "leite" $(0,11)$, amêndoa $(0,11)$, alimento para animais domésticos $(0,11)$, construção de telhados $(0,11)$ e óleo $(0,10)$; para o babaçu, os quatro primeiros usos também se destacaram, com valores semelhantes: "leite" $(0,15)$; óleo $(0,15)$; amêndoa $(0,15)$; construção de telhados $(0,14)$ e armação de paredes $(0,10)$. Menor concordância foi verificada para os demais usos, citados por menor número de informantes.

Os valores encontrados evidenciam, portanto, que as categorias que mais contribuem para o uso do ouricuri e do babaçu nos sítios estudados são alimento do homem $\left(\mathrm{UDs}_{O p h} 0,32 ; \mathrm{UDs}_{S c} 0,27\right)$ e artesanato $\left(\mathrm{UDs}_{O p h} 0,24\right.$; $\mathrm{UDs}_{S c}$ 0,27), com índices semelhantes para as duas espécies. A categoria construção atingiu valores bem mais baixos $\left(\mathrm{UDs}_{S c} 0,15\right.$; UDs $\left.0,12{ }_{\text {ph }}\right)$ e o uso nas demais categorias parece ser muito raro, considerando-se os índices obtidos para as duas espécies (Tab. 4).

Analisando-se como os diferentes usos contribuem para o uso total de cada uma das espécies estudadas, obteve-se para ambas o valor máximo (UEs 1,0) para a categoria alimento do homem. A categoria artesanato também atingiu valores elevados, tanto para o ouricuri (UEs 1,0) quanto para o babaçu (UEs 0,75 ). Na categoria medicinal os valores ainda são elevados $\left(\mathrm{UEs}_{s c} 0,66\right.$; $\left.\mathrm{UEs}_{O p h} 0,50\right)$, bem como na categoria construção para o ouricuri $\left(\mathrm{UEs}_{S c} 0,55\right)$, porém nesta última foi baixo $\left(\mathrm{UEs}_{O p h}\right.$ $0,37)$ para o babaçu. A concordância entre os informantes é bem menor para as demais categorias, como mostram os respectivos valores, inferiores a 0,30 (Tab. 4).

Segundo Byg \& Baslev (2001), os estudos etnobotânicos realizados em diferentes países têm evidenciado que a importância local de uma planta é função da quantidade de usos existentes na comunidade; a validade desta afirmativa foi testada positivamente por estes autores, que estudaram as espécies de palmeiras utilizadas em três povoamentos situados nos arredores de áreas de floresta úmidas e semi-úmidas protegidas, em Madagascar. Segundo eles, a importância de uma planta para um determinado grupo humano seria, então, o produto da diversidade de aproveitamento da espécie. Todavia, o mesmo estudo demonstrou que a contribuição dos diferentes usos da planta, varia muito para uma espécie com elevado número de usos, pois um ou dois desses usos seriam os responsáveis pela maioria das citações e os demais são apenas mencionados por uns poucos informantes. Analisando as citações para os usos enquadrados nas diferentes categorias verificou-se que 
Tabela 3. Valor de consenso para um propósito (PCs) relativo a Syagrus coronata (ouricuri) e Orbignya phalerata (babaçu) no município de Buíque, PE, Brasil. *em ordem decrescente de valores do Ouricuri.

\begin{tabular}{lcc}
\hline Propósito & *Ouricuri & Babaçu \\
\hline "Leite do coco" & 0,11446 & 0,15301 \\
Amêndoa & 0,11446 & 0,14754 \\
Alimento de animal doméstico & 0,10843 & 0,07377 \\
Telhado & 0,10643 & 0,14481 \\
Óleo & 0,10442 & 0,15301 \\
Alimento de animal silvestre & 0,06827 & 0,04645 \\
Vassoura & 0,05823 & 0,01093 \\
Chapéu & 0,05422 & 0,02459 \\
Parede & 0,05422 & 0,10383 \\
Abano & 0,04217 & 0,01366 \\
Farinha & 0,04016 & 0,08197 \\
Esteira & 0,03615 & 0,04645 \\
Cesta & 0,01606 & 0,01366 \\
Bolsa & 0,01406 & 0,00273 \\
Cocada & 0,01205 & 0,08197 \\
Mesocarpo & 0,01205 & - \\
Doce & 0,01205 & 0,01093 \\
Colírio & 0,00803 & - \\
Mourão & 0,00803 & 0,01093 \\
Rancho & 0,00602 & - \\
Tapete & 0,00402 & - \\
Peneira & 0,00402 & - \\
Corda & 0,00402 & - \\
Pano branco & 0,00402 & 0,00546 \\
Embuzada & 0,00402 & 0,0082 \\
Banheiro & 0,00402 & - \\
Lenha & 0,00402 & 0,01093 \\
Tratar ferida & 0,00201 & 0,00546 \\
Dor de coluna & 0,00201 & - \\
Fano preto & 0,00201 & 0,00273 \\
Barraca & 0,00201 & - \\
Laxante & 0,00201 & - \\
Azeite & - & 0,00273 \\
Carvão & -00273 \\
\hline
\end{tabular}

alguns contribuem fortemente para o número total de citações para a utilização de frutos, folhas e estipe de ouricuri e babaçu nas categorias alimento para o homem, artesanato e construção, que se destacaram das demais na comunidade (Fig. 2-4).

No estudo realizado em Madagascar, Byg \& Baslev (2001) observaram que as plantas consideradas como importantes e usadas para muitos propósitos eram utilizadas por mais pessoas do que aquelas que não eram bem valorizadas ou tinham poucos usos. Os valores de equitabilidade dos informantes encontrados pelos referidos autores para as diferentes espécies de palmeiras estudadas variaram entre 0,29-1,0, com uma média de 0,66 e desvio padrão $=0,22$, indicando que todas as pessoas que citaram uma certa espécie conheciam mais ou menos o mesmo número de usos.

Avaliando-se o índice de valor da diversidade do informante (IDs), que mede quanto cada informante conhece do total de usos, constata-se que baixos valores foram registrados para o babaçu na comunidade estudada, pois apenas um informante mostrou conhecer mais da metade do total de usos citados para esta palmeira (IDs 0,52), e mais da metade dos índices (65\%), variaram entre 0,20-0,28 (Tab.1). Os valores de IDs para o ouricuri foram mais baixos que os registrados para o babaçu e apenas três informantes atingiram valores entre $0,45-0,48,13 \%$ obtiveram índices entre 0,33 e 0,39 e a metade situou-se na faixa de 0,21-0,30.

Para o babaçu, apenas dois informantes atingiram o valor máximo do consenso de uso (UCs) $(1,0)$ ou próximo a ele $(0,94), 31 \%$ atingiram valores entre $0,30-0,38,36 \%$ atingiram $0,46-0,53$ e $17 \%$ obtiveram índices entre 0,61 e 0,76 ; considerando o ouricuri, apenas um informante atingiu o valor máximo $(1,0)$, três obtiveram índices entre 0,81-0,93, 28\% registraram índices entre $0,12-0,37,36 \%$ entre $0,43-0,56$ e $18 \%$ atingiram índices entre $0,62-0,75$. O consenso de uso mostrou que as duas espécies de palmeira são conhecidas por todos (ouricuri) ou quase todos (babaçu) os informantes, que atribuem em média entre 5-8 usos para cada espécie (Fig. 2-4).

O presente estudo demonstrou que, na comunidade estudada, situada no agreste de Pernambuco, o ouricuri e o babaçu são utilizados para vários propósitos e devem ser considerados como espécies importantes na comunidade rural estudada, sendo seu valor baseado principalmente no uso alimentício do fruto e da amêndoa, amplamente conhecido e ainda em uso corrente entre os informantes. Considerando que a importância das duas espécies centra-se principalmente no uso dos frutos, a pressão devida à exploração deve ser controlada, para permitir o desenvolvimento de novos indivíduos, evitando o envelhecimento das populações locais.

Os membros da comunidade demonstraram preocupação quanto à conservação das duas espécies estudadas. Ao contrário do observado em muitas outras populações que utilizam palmeiras (Velásquez-Runk 2001) a técnica de coleta empregada na comunidade estudada

Tabela 4. Índices de diversidade (UDs) e equitabilidade (UEs) de uso de Syagrus coronata (ouricuri) e Orbignya phalerata (babaçu) no município de Buíque, PE, Brasil.

\begin{tabular}{llllll}
\hline \multirow{2}{*}{ Categorias } & \multicolumn{2}{c}{ Babaçu } & & \multirow{2}{*}{ Ouricuri } \\
\cline { 2 - 3 } & UDs & UEs & & UDs & UEs \\
\hline Alimento do homem & 0,32 & 1,00 & & 0,27 & 1,00 \\
Alimento de animal doméstico & 0,04 & 0,12 & & 0,06 & 0,22 \\
Alimento de animal silvestre & 0,04 & 0,12 & & 0,03 & 0,11 \\
Construção & 0,12 & 0,37 & & 0,15 & 0,55 \\
Artesanato & 0,24 & 0,75 & & 0,27 & 1,00 \\
Combustível & 0,08 & 0,25 & & 0,03 & 0,11 \\
Medicinal & 0,16 & 0,50 & & 0,18 & 0,66
\end{tabular}


é não destrutiva, pois são tiradas as folhas mais velhas, poupando as mais novas (as "do olho", como falam os informantes). Quase todos os informantes relataram que a coleta dos frutos é feita apenas quando os coquinhos caem no chão e apenas uns poucos disseram que coletam os frutos maduros do ouricuri ainda presos na planta.

Sinais da ocorrência de erosão do conhecimento tradicional foram encontrados, pois muitos informantes, entre jovens e idosos, comentaram que sabiam de um determinado uso por ouvir dizer, porém não mais o praticavam. O uso atual restringe-se quase que ao emprego das folhas para construção de "ranchos" (cobertura para abrigar animais) e do óleo e do "leite do coco" na alimentação.

Durante as entrevistas percebeu-se que as duas espécies de palmeira poderiam contribuir positivamente para a economia da comunidade, mas a intensidade de exploração do recurso está sendo influenciada pelas alterações do ambiente natural e condições sócio-econômicas vigentes atualmente; muitos deles, por exemplo, receosos de terem suas terras desapropriadas com a implantação do Parque Nacional Vale do Catimbau, estão vendendo suas propriedades a uma fábrica de farinha que vem causando a substituição da vegetação nativa pela plantação de mandioca (Manihot esculenta Crantz).

\section{Agradecimentos}

Os autores agradecem aos colegas Amaro de Castro Lyra Neto e Marina de Sá Costa Lima, pelo apoio durante a execução do trabalho; à professora Dra. Suely Luna, pelas sugestões e apresentação de moradores da localidade estudada; à comunidade dos Sítios Baixa Grande e do Serrote Preto, em especial, na pessoa de Maria Francilda Andrade Santos, pela hospitalidade e disponibilidade; ao CNPq, pela bolsa concedida ao primeiro autor.

\section{Referências bibliográficas}

Albuquerque, U.P. \& Lucena, R.F.P. 2004. Métodos e técnicas na pesquisa etnobotânica. Recife, NUPEEA.

Amorim, E.; Matias, J.E.F.; Coelho, J.C.U.; Campos, A.C.L.; Stahlke Jr., H.J.; Timi, J.R.R.; Rocha, L.C. A.; Moreira, A.T.R.; Rispoli, D.Z. \& Ferreira, L.M. 2006. Efeito do uso tópico do extrato aquoso de Orbignya phalerata (babaçu) na cicatrização de feridas cutâneas - estudo controlado em ratos. Acta Cirúrgica Brasileira 21: 67-76.

Balick, M.J. 1984. Ethnobotany of palms in the neotropics. Advances in Economic Botany 1: 9-23.

Bondar, G.O. 1938. O Licurizeiro e suas potencialidades na economia brasileira. Boletim do Instituto Central de Fomento Econômico da Bahia 2: 1-18.
Byg, A. \& Baslev, H. 2001. Diversity and use of palms in Zahamena, eastern Madagascar. Biodiversity and Conservation 10: 951-970.

Costa Neto, E.M. 2004. Estudos etnoentomológicos no estado da Bahia, Brasil: uma homenagem aos 50 anos do campo de pesquisa. Biotemas 17: 117-149.

Crespaldi, I.C.; Almeida-Murandian, L.B.; Rios, M.D.G.; Penteado, M.V.C. \& Salatino, A. 2001. Composição nutricional do fruto de licuri (Syagrus coronata (Martius) Becari). Revista Brasileira de Botânica 24: 155-159.

Gazzaneo, L.R.S.; Lucena, R.F.P. \& Albuquerque, U.P. 2005. Knowledge and use of medicinal plants by local specialists in a region of Atlantic Forest in the state of Pernambuco (Northeastern Brasil). Journal of Ethnobiology and Ethnomedicine 1: 1-9.

Gomes, A.P.S.; Rodal, M.J.N. \& Melo, A.L. 2006. Florística e fitogeografia da vegetação arbustiva subcaducifólia da Chapada de São José, Buíque, PE, Brasil. Acta Botanica Brasilica 20: 37-48.

Gonçalves, C.M.; Lopes, K.G.S.; Crepaldi, I.C.; Góes Neto, A. \& Uetanabaro, A.P.T. 2005. Ocorrência de microrganismos em ração animal preparada artesanalmente a partir do licuri (Syagrus coronata). Sitientibus, Série Ciências Biológicas 5: 53-55.

IBGE 2000. www.ibge.org.br. (Acessado em: 12/01/2007).

Leal, I.R.; Silva, J.M.C.; Tabarelli, M. \& Lacher Jr., T.E. 2005. Mudando o curso da conservação da biodiversidade na Caatinga do Nordeste do Brasil. Megadiversidade 1: 139-146.

Macía, M.J. 2004. Multiplicity in palm uses by the Huaorani of Amazonian Ecuador. Botanical Journal of the Linnean Society 144: 149-159.

Medeiros-Costa, J.T. 2002. As espécies de palmeiras (Arecaceae) do Estado de Pernambuco, Brasil. Pp. 229-236. In: M. Tabarelli \& J.M.C. Silva (eds.). Diagnóstico da Biodiversidade de Pernambuco. Recife, SECTMA \& Massangana.

Phillips, O. 1996. Some quantitative methods for analyzing ethnobotanical knowledge. Pp.171-197. In: M. Alexiades (ed.). Selected guidelines for ethnobotanical research: a field manual. New York, New York Botanical Garden.

Phillips, O. \& Gentry, A.H. 1993. The useful plants of Tambopata, Peru: II additional hypothesis testing in quantitative ethnobotany. Economic Botany 47: 33-43.

Pinheiro, C.U.B.; Santos, V.M. \& Ferreira F.R.R. 2005. Usos de subsistência de espécies vegetais na região da baixada maranhense. Amazônia: Ciência \& Desenvolvimento 1: 235-250.

Rocha, A.E.S. \& Silva, M.F.F. 2005. Aspectos fitossociológicos, florísticos e etnobotânicos das palmeiras (Arecaceae) de floresta secundária no município de Bragança, PA, Brasil. Acta Botanica Brasilica 19: 657-667.

Schwenk, L.M. \& Silva, C.J. 2000. A etnobotânica da Morraria Mimoso no pantanal de Mato Grosso. Pp. 1-27. In: Anais do III Simpósio sobre recursos naturais e sócio-econômicos do Pantanal. Corumbá.

Silva, J.C.; Barrichelo, L.E.G. \& Brito, J.O. 1986. Endocarpos de Babaçu e de Macaúba comparados a madeira de Eucalyptus grandis para a produção de carvão vegetal. Ipef 34: 31-34.

Silva, A.J.R. \& Andrade, L.H.C. 2005. Etnobotânica nordestina: estudo comparativo da relação entre comunidades e vegetação na Zona do Litoral-Mata do Estado de Pernambuco, Brasil. Acta Botanica Brasilica 19: 45-60.

Silva, V.A.; Andrade, L.H.C. \& Albuquerque, U.P. 2006. Revising the Cultural Significance index: The Case of the Fulni-ô in Northeastern Brazil. Field Methods 18: 98-108.

Velásquez-Runk, J. 2001. Wounaan and Emberá use and management of the fiber Palm Astrocaryum standleyanum (Arecaceae) for basketry in Eastern Panamá. Economic Botany 55: 72-82. 